\title{
Evaluation and demonstration of maize shellers for small-scale farmers
}

\begin{abstract}
Reducing post harvest losses is a central task to ensure food security and increase income of smallholder farmers as well as facilitate food availability to local and international markets. Maize is one of the major food crops produced in Ethiopia and with high post losses. The stages of post harvest loss span from harvesting to final consumption. Threshing or shelling is one of the major stages of post harvest loss in maize production. Traditional threshing incurs huge loss, is full of drudgery and consumes time. To reduce the loss and improve the working condition of our farmers, Bahir Dar Agricultural Mechanization and Food Science Research Center (BAMFSRC) adapted two maize Shellers; viz, cylindrical (also known as handheld) and motorized Shellers. These technologies were demonstrated and evaluated by farmers in different parts of Amhara Region. The results indicated that these technologies, part of the small and medium mechanization tools, are compatible to the smallholders. Scaling out and up of these technologies through supply and demand driven mechanisms is essential to realize the benefits from employing the technologies.
\end{abstract}

Volume I Issue 3 - 2017

\author{
Dagninet Amare,' Wolelaw Endalew, ${ }^{2}$ Negese \\ Yayu, ${ }^{2}$ Asmamaw Endeblihatu, ${ }^{3}$ Worku \\ Biweta, ${ }^{3}$ Abu Tefera, ${ }^{3}$ Solomon Tekeste ${ }^{3}$ \\ 'Amhara Agricultural Research Institute, Ethiopia \\ ${ }^{2}$ Bahir Dar University, Ethiopia \\ ${ }^{3}$ Amhara Metal Engineering and Machine Technology \\ Development Enterprise, Ethiopia
}

\begin{abstract}
Correspondence: Dagninet Amare, Amhara Agricultura Research Institute, Bahir Dar-Ethiopia, Ethiopia, Email dagnnet@gmail.com
\end{abstract}

Received: October 13, 2017| Published: October 24, 2017

Keywords: handheld maize sheller, motorized thresher, traditional shelling

\section{Introduction}

Maize (Zea mays L.) said to have originated in tropical zones of America is the third most important cereal crop in the world, next to wheat and rice. World maize production is estimated 856million tons in 2011/2012 (Ashwin and Shaik, 2014). Maize contains starch $(60 \%-880 \%)$, protein $(88 \%-12 \%)$, fat $(3 \%-5 \%)$ and minerals $(1 \%$ $5 \%$ ) Sexena et al. ${ }^{1}$ It is the cheapest source of starch, protein nutrients for human being and animals and serving as a basic raw material for the production of starch, oil and protein, alcoholic beverages, food sweeteners and, more recently, fuel. In Ethiopia, maize grows from moisture stress to high rainfall areas and from lowlands to the highlands. It is one of the most important cereal crops grown in the country and is the main staple food in rural areas. It accounts over $14 \%$ and $18 \%$ in terms of land area coverage and productivity respectively with higher annual growth rate. Ethiopia is the largest maize producer in Eastern and Southern Africa. Over 8 small holder farmers are engaged in maize production and this accounts $28 \%$ the total cereal production. The total maize production in 2010/2011 was estimated 4.98 million tons Demeke et al. ${ }^{2}$ The overall productivity of maize is affected by many factors including lack of post-harvest technologies, such as shelling. Maize kernels should be removed from cob to be used as seeds, prepare value addition, improve handling and storage as well as maintain its quality. Shelling which refers removal of kernel from cob is an important post-harvest operation in maize production. Shelling can be carried out in the field or on the farm. Maize shelling is difficult at moisture content above $25 \%$, with this moisture content, grain stripping efficiency is very poor with high operational energy and causing mechanical damage to the seed. A more efficient shelling is achieved when the grain has been suitably dry to 13 to $14 \%$ moisture content Danilo et al. ${ }^{3}$ Maize shelling in Ethiopia is mainly carried out using traditional methods. The most commonly employed methods include manual rubbing maize cobs against one another, using human finger, biting the cob with wooden plank, treading with animal. Likewise the grain can be detached from the cob with the use of pestle and mortal. All these traditional maize shelling methods are highly tedious, inefficient; do not support largescale shelling of maize requiring a lot of labor and time with low productivity as a worker can only shell a few kilograms per hour. ${ }^{4}$

Kernel damages in the form of bruiser, crack or breakage are inevitable during these shelling methods. Such kernel damage facilitates the infestation of field pests during storage. Attempts were in the past to develop and introduce engine driven and tractor driven high capacity Sheller's. The technology though perfect is not within the reach of marginal farmers. Existing motorized Sheller are too expensive to be purchased by resource poor smallholder farmers. The cost of hiring to get the service is even high for most farmers. Bahir Dar Agricultural Mechanization and Food Science Research Center has adapted cylindrical hand operated and motorized maize Shellers and preliminary demonstration reveals that farmers have shown interest to use them.

Thus, there is a need to introduce this implement that reduces postharvest loss, increase labor efficiency in time and avoid the drudgery and harms to the hand of men and women farmers. Thus, there was a need to demonstrate both of the machines and collect feedback from farmers that are useful for future promotion and modification activities. This was supported by the national strategy that states further strengthening the introduction of suitable post-harvest tools. Therefore, this research activity is conducted; (1) to create awareness in hand-held maize Sheller, and (2) to collect farmers' opinion on the future dissemination and use of the technologies and hence contribute to the improvement of the productivity and drudgery of smallholder maize producing farmers.

\section{Experimental sites}

This experiment was conducted in Amhara region, North West Ethiopia. Demonstration sites were selected purposively based on intensity of production in collaboration with experts from Woreda 
agricultural offices. The demonstration sites for cylindrical Sheller were Shina Tsion kebele from Libo-Kemkem Woreda, Abua-kokit and Diba-Sefatra kebeles from Fogera Woreda. Burie woreda was the demonstration site for motorized maize Sheller. Both cylindrical and motorized threshers were displayed in the demonstration at farms and farmers training center. Farmers were presented on the process of threshing and maize shelling.

\section{Handheld maize sheller description}

The Sheller is made of steel tube and internally welded with four steel vanes oriented at $90^{\circ} \mathrm{C}$ to the tube wall. The vanes are provided with a tapper of about1:7 to accommodate the tapered cob. The length of the cylindrical Sheller is $75 \mathrm{~mm}$ and average diameter is $80 \mathrm{~mm}$. While rotating the maize cob and holding firmly the steel tube on the other hand a single person operates the Sheller. The overall mass of the Sheller is $0.2 \mathrm{Kg}$ (Figure 1).

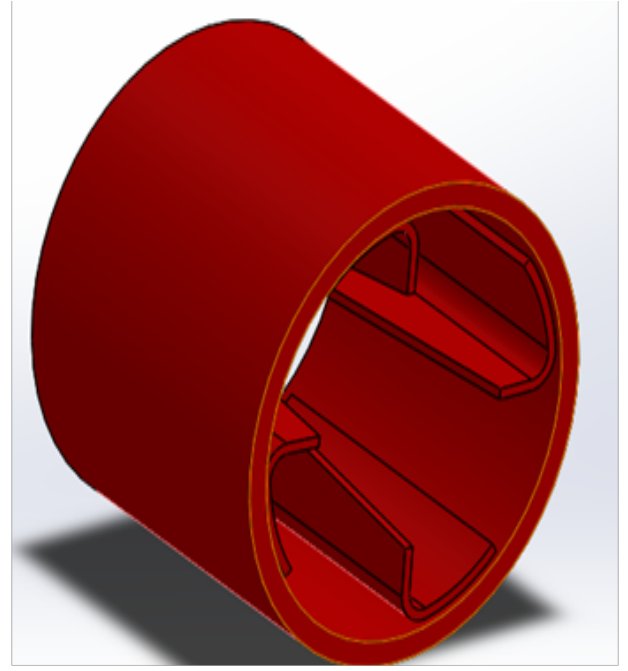

Figure I Handheld maize Sheller.

\section{Data collection and analysis}

Prior to the experimental activities, theoretical and practical training were given to the host farmers so that they are familiar with the operation of Sheller. Samples were taken to test the thresher and Sheller efficiency and capacity. Manual cylindrical Sheller and stonerubbing were conducted with different genders. Semi-structured questionnaire was used to collect farmers' opinion during the process. Survey data was collected for most of the traditional maize shelling methods. For motorized thresher of maize, grain from grain and cob outlet as well as plain sieve was measured. Three separate trials were done and 3 samples from each trial were taken in 10seconds time length. Weight of threshed and unthreshed grain from plain sieve, cob and grain out-let is measured to estimate threshing efficiency. Grain (3) samples from each maize separate trial were taken and weight of broken grain measured to estimate thresher breakage. Grain from grain out-let, chaff outlet and plain sieve were taken and considered accordingly. Total grain output was weighed to estimate sample similarity in both of the demonstrations. Moreover, FAO test procedures were done to ensure machine efficiency. Opinions, views and response of the participants about the technology as compared with the traditional practice were collected by interviewing. Data was analyzed using qualitative analysis and descriptive statistics. Ms Excel 2007 and Stata were used for the data analysis.

\section{Results and discussion}

The conventional methods used in the localities were recognized in this study to evaluate the comparative advantage of these methods against the introduced technologies. The traditional methods of shelling included in this study were; animal trampling, beating by stick and stone rub. The results are presented as survey (i.e. for traditional methods) and experimental results (i.e. for cylindrical and motorized Shellers) based on data collection procedure.

\section{Survey results}

\section{Animal trampling}

Trampling is the treading of animals over the crop. It requires a minimum of 5 oxen for $2 \mathrm{hrs}$ are required to thresh a size of $21 \mathrm{qts}$ of maize. 11 persons are required for $9 \mathrm{hrs}$ to direct oxen, sort the cob and thresh the unthreshed maize respectively. Trampling speeds up threshing operation and avoids spread of yield. Nevertheless it reduces the quality of yield obtained since it is mixed with soil along with harming the hoof of animals. Maize is threshed in other ways alternatively.

\section{Beating by stick (“dulla”)}

This operation requires more labor than others and damages seeds. Using the plastic sack to avoid spread, a total of 12 persons and five (5) sacks are used to thresh 21qts of maize in $9 \mathrm{hrs}$ time length. In this operation males are mostly the actors, as it requires more force. Even thou it consumes more labor it is speedier than others.

\section{Stone-rub}

The stone can be, any stone, collected from the area given it has groves. It doesn't crush and spread maize yield. More force is required to thresh maize of larger cob size. Stone-rub occasionally rubs the hands of the individuals in the operation. Threshing of 21qts of maize using stone-rub requires 6.15 persons for $9 \mathrm{hrs}$. With no cost, it is preferable than the other traditional methods.

\section{Experimental results}

\section{Hand held (cylindrical manual) sheller}

Hand held Maize Sheller is a light, simply constructed, and inexpensive maize Sheller made from steel tubes with shelling teeth fixed internally. With this Sheller, maize cob held on one hand is rotated against a stationary shelling device held on the other hand, or vice versa. In the process, the teeth of the Sheller entangle and remove the grain from the cob. It eliminates the usual pain experienced when shelling by hand. Shelling maize is becoming a laborious task for hybrid maize producers mainly when seasonal labor shortage is at peak. In order to reduce drudgery in small scale shelling, a comparative test was conducted between traditional and simple hand held maize Sheller on BH-540 improved maize variety for 15 minutes. The shelling efficiency and capacity of the Sheller was collected from 10 trainees (three males and seven females) at Diba Safetra Kebele, Diba Village. Further, hand picking, considered as traditional in this experiment, is presented comparatively (Table 1). Further, Levene's test of homogeneity of variances (Table 2 ) of the two groups showed the presence of significant difference $(\delta 2=7.71, \mathrm{p}=0.01)$ among the two groups, traditional and cylindrical Shellers. The average output of hand held maize Sheller was $20.32 \mathrm{Kg} / \mathrm{hr}$ whereas traditional shelling by hand was $9.12 \mathrm{Kg} / \mathrm{hr}$. So it requires roughly 104 and 230 
adult labor/persons to shell a size of 21qts of maize in one $1 \mathrm{hr}$ length with cylindrical and traditional Sheller, respectively. The thresher has an estimated service life of 5yrs and cost of 30birr. Of course, the efficiency of the Sheller differs depending on the individuals ergonometric as well as the maize cob conditions as demonstrated by Dagninet et al. ${ }^{5}$ with a shelling efficiency of $25.7 \mathrm{~kg}$ of maize in $1 \mathrm{hr}$. Cylindrical thresher creates work burden on the farmers to select cob of maize that fits to the size of the technology, as the height of the internal parts don't thresh maize of thicker cob. The heaviness of the thresher impedes easy maneuverings. It also rubs the hands of persons when using for a longer period; which requires use of additional materials that prevent rubbing. Moreover it exposes for tiresome to operate for longer period, than traditional methods including stonerub. This is so because farmers cannot use their full energy in the case of cylindrical one while it is possible in traditional methods. Thou cylindrical thresher does not crush and spread maize. The SPSS 16 output shows great discrepancy between the two threshers at a maximum capacity an individual can perform (with the assumption that initially people will work at highest level since no fatigue).

Table I Data collected from hand maize Sheller compared with the traditional shelling practice

\begin{tabular}{|c|c|c|c|c|c|c|c|c|}
\hline \multirow{2}{*}{$\begin{array}{l}\text { Test } \\
\text { no }\end{array}$} & \multicolumn{4}{|c|}{ Hand maize sheller } & \multicolumn{4}{|c|}{ Traditional shelling by their thumb tip/handpicking } \\
\hline & $\begin{array}{l}\text { Testing } \\
\text { time(minute) }\end{array}$ & $\begin{array}{l}\text { Shelled } \\
\text { amount(Kg) }\end{array}$ & $\begin{array}{l}\text { Shelling } \\
\text { Efficiency\% }\end{array}$ & $\begin{array}{l}\text { Shelling } \\
\text { capacity (Kg/ } \\
\text { hr) }\end{array}$ & $\begin{array}{l}\text { Testing } \\
\text { time(minute) }\end{array}$ & $\begin{array}{l}\text { Shelled } \\
\text { amount(Kg) }\end{array}$ & $\begin{array}{l}\text { Shelling } \\
\text { Efficiency\% }\end{array}$ & $\begin{array}{l}\text { Shelling } \\
\text { capacity }(\mathrm{Kg} / \mathrm{hr})\end{array}$ \\
\hline I & 15 & 4 & 100 & 16 & 15 & 2.6 & 100 & 10.4 \\
\hline 2 & 15 & 6.2 & 100 & 24.8 & 15 & 2.1 & 100 & 8.4 \\
\hline 3 & 15 & 3.4 & 100 & 13.6 & 15 & 1 & 100 & 4 \\
\hline 4 & 15 & 5 & 100 & 20 & 15 & 2.6 & 100 & 10.4 \\
\hline 5 & 15 & 4.3 & 100 & 17.2 & 15 & 2.1 & 100 & 8.4 \\
\hline 6 & 15 & 5.2 & 100 & 20.8 & 15 & 2.2 & 100 & 8.8 \\
\hline 7 & 15 & 5.8 & 100 & 23.2 & 15 & 2.3 & 100 & 9.2 \\
\hline 8 & 15 & 6.4 & 100 & 25.6 & 15 & 2.9 & 100 & 11.2 \\
\hline 9 & 15 & 4.2 & 100 & 16.8 & 15 & 2.2 & 100 & 8.8 \\
\hline 10 & 15 & 6.3 & 100 & 25.2 & 15 & 2.8 & 100 & 11.2 \\
\hline Average & 15 & 5.08 & 100 & 20.32 & 15 & 2.28 & 100 & 9.12 \\
\hline
\end{tabular}

Table 2 ANOVA table

\begin{tabular}{llllll}
\hline Shell capacity & Sum of squares & Df & Mean square & F & Sig \\
\hline Between Groups & 631.688 & I & 631.688 & 55.273 & 0 \\
Within Groups & 205.712 & 18 & 11.428 & \\
Total & 837.4 & 19 & & \\
\hline
\end{tabular}

\section{Motorized sheller}

Motorized thresher with feeders of 11 persons ( 2 on the side of grain outlet, 1 on the side of cob outlet and 8 to feed the machine) has an output capacity of $41 \mathrm{qts} / \mathrm{hr}$ of maize on average. The threshing efficiency for maize is $98.3 \%$ with breakage of $4.99 \%$ and excellent cleaning efficiency. The machinist being permanent on both cases, the fuel requirement of the thresher is $3.125 \mathrm{lit} / \mathrm{hr}$ for maize. The loss in spread that comes from the plain sieve and chaff/cob outlet is not considered as a loss since farmers easily collected it. Breakage was not considered as loss except to smaller extent as the farmers recognized it as part of the food to be processed with other products (Table 3) (Table 4). In summary, the motorized thresher has a threshing efficiency of $98.3 \%$, where as the $1.73 \%$ is unthreshed output (maize seeds are not separated from the cob) and an output capacity of $41 \mathrm{qthr}^{-1}$. The unthreshed grain form motorized thresher requires 1.87, 2.76 and 3.65hrs of an individual to separate the grain from the cob by using stone rub, cylindrical maize Sheller and beating by stick, respectively. Given, the breakage and quality degradation, we recommend the use of the cylindrical maize Sheller amongst these options. However, it is not without notice that the motorized Sheller is more advantageous in sorghum threshing areas. The thresher has an output capacity of $12.5 \mathrm{qts} / \mathrm{hr}$ of sorghum. It requires 10 persons (i.e. 1 person in the side of grain outlet, 1 on the chaff outlet and 8 persons to feed the machine) on average to thresh sorghum with threshing and cleaning efficiency of $93.51 \%$ and $88.18 \%$ and no significant breakage with a fuel consumption of $1.473 \mathrm{lit} / \mathrm{hr}$ (Table 5). 
Table 3 Data for motorized maize shelling (each trial was conducted for 10 seconds time)

\begin{tabular}{|c|c|c|c|c|c|c|c|}
\hline \multirow{2}{*}{ Location } & \multirow{2}{*}{ Crop } & \multirow{2}{*}{ Variety } & \multirow{2}{*}{ Trials } & \multicolumn{3}{|c|}{ Output(kg) } & \multirow{2}{*}{$\begin{array}{l}\text { Wt. of threshed \& unthreshed } \\
\text { grain from cob outlet after } \\
\text { hand threshing(kg) }\end{array}$} \\
\hline & & & & Grain & Cob & Plain sieve & \\
\hline & & & I & 7 & 0.095 & 0.0297 & 3 \\
\hline & & $\mathrm{BH} 660$ & 2 & 7.7 & 0.114 & 0.0189 & 3.3 \\
\hline & & & 3 & 11 & 0.091 & - & 4 \\
\hline & & & 1 & 12.7 & 0.097 & - & 4 \\
\hline \multirow[t]{5}{*}{ Bure } & Maize & $\mathrm{BH} 540$ & 2 & 10 & 0.095 & - & 3.3 \\
\hline & & & 3 & 12 & 0.357 & - & 4 \\
\hline & & & 1 & 11 & 0.421 & 0.344 & 5 \\
\hline & & Local & 2 & 14 & 0.448 & 0.33 & 4 \\
\hline & & & 3 & 13 & 0.219 & 0.306 & 5 \\
\hline
\end{tabular}

Table 4 Motorized Sheller maize breakage

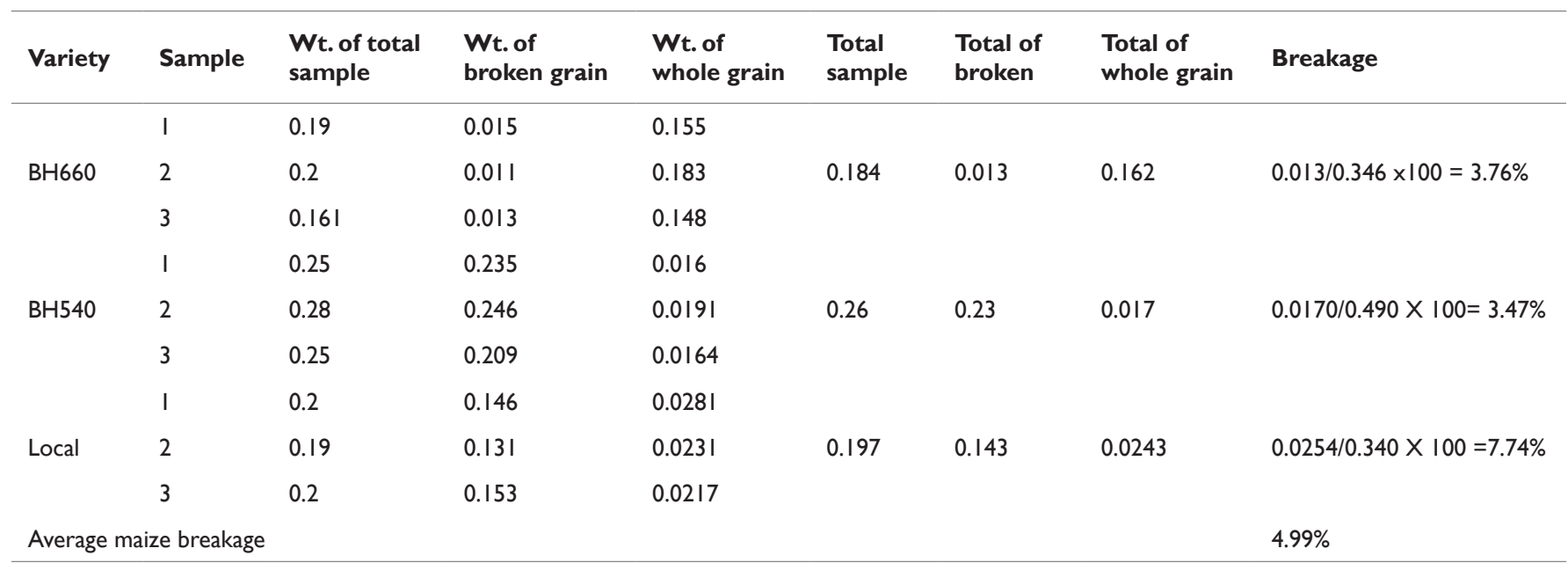

Table 5 FAO test procedure for motorized maize thresher

\begin{tabular}{|c|c|c|c|}
\hline \multirow[b]{2}{*}{ Sample Measurements } & \multicolumn{3}{|c|}{ Maize sheller } \\
\hline & Sample-I & Sample-2 & Sample-3 \\
\hline Crop/Varity & Maize & & \\
\hline a. Time of sampling run (sec) & 10 & 10 & 10 \\
\hline b.Weight of threshed grain at main grain out let per unit time $(\mathrm{kg})$ & 8.6 & 11.6 & 12.7 \\
\hline c.Weight of threshed grain at all others grain out let per unit time $(\mathrm{kg})$ & 0.32 & 0.28 & 0.69 \\
\hline j.Weight of un threshed grain at all others out let per unit time $(\mathrm{kg})$ & 0.1 & 0.18 & 0.36 \\
\hline \multicolumn{4}{|l|}{ Sample results } \\
\hline I. Total grain output $(A=b+c d)(k g)$ & 9.02 & 12.06 & 13.75 \\
\hline 2. Percentage of un-threshed grain $(\mathrm{N}=\mathrm{j} \backslash \mathrm{A} \times 100)(\%)$ & I.I & 1.5 & 2.6 \\
\hline 3.Threshing efficiency $(100-N)(\%)$ & 98.9 & 98.5 & 97.4 \\
\hline 9. Output capacity $(\mathrm{W}=\mathrm{b}+\mathrm{c})(\mathrm{kg} / \mathrm{hr})$ & 3211 & 4277 & 4820 \\
\hline
\end{tabular}




\section{Discussion}

\section{Physical analysis}

The hand held maize Sheller threshing performance in this regard was more than two folds as compared to the traditional shelling practice. Shelling efficiency of the Sheller was $100 \%$. Samples were taken randomly from the shelled cob to see how much grain left over with the cob but any of the cobs doesn't contain the grain on it. In addition to its higher shelling efficiency the Sheller doesn't break the maize grain. There was no grain broken during shelling as also confirmed by farmers and observation by the researchers during the experiment. Therefore, the Sheller doesn't break the maize grain and breakage was nil. This study hence lacks to measure the marketable and non-marketable produce, the spread out in all cases of the shelling, the quality degradation and labor required for sorting this product for better marketing.

\section{Economic analysis}

The comparative advantage in terms of partial budget is done for all traditional methods and cylindrical manual thresher in comparison to motorized thresher for threshing a size of 21qts of maize and 20qts of sorghum; based on the capacity of trampling. Working days per year for motorized thresher is assumed 90days and 6hrs per day. Motorized thresher, with estimated service life of 10yrs and cost of 50700ETB, is better compared to the traditional methods. Nevertheless, it requires more labor for feeding, protecting the spread and pushing down the crop as it doesn't hold it. Therefore the farmers wanted the inlet be circular and the blowing part be improved so that it protects spread and blow on the feeders. The open space along the horizontal of the inlet drops threshed \& unthreshed and dust like material and creates serious problem on the threshing operation. It requires more speed to feed the machine for full performance; otherwise it spreads the threshed seeds back to the inlet and consumes similar amount of fuel to thresh lesser quantity.

The advantage of motorized thresher seems insignificant, in monetary terms, compared to stone-rub. Even then, the hardness of the work with stone-rub, easy tiresome of individuals along with discomfort in rubbing hands makes motorized thresher preferable than stone-rub. Similarly, motorized thresher is preferred than animal trampling due to the economic benefit and shortage of animals and damage to kernels and hoof of animals. Stick biting usually requires more labor to thresh and people get tired easily. Hence, it is not practical to thresh the specified amount within the time limit. Thus with the prevailing economic benefit and reduction of breakage loss, motorized thresher is preferable than stick biting. Manual cylindrical thresher shows economic deficiency relative to motorized thresher. Motorized maize thresher is preferred than manual cylindrical maize Sheller due to the economic gains, time wastage in selection of cob size as well as difficulty of easy maneuverings. For sorghum, motorized thresher is more advantages than animal trampling. Generally, with modifications to be introduced, motorized thresher bears crucial for maize shelling in the region (Table 6).

\section{Farmers opinion}

The farmers were very interested on hand held maize as well as motorized Shellers. They indicated that the cylindrical Sheller can be fabricated by home artisans from local materials, it was cheap and suitable for small scale farmers, it has minimum damage and loss to the kernels, it is more efficient compared to direct hand shelling, it reduce work tedium and finger soreness and required no special skills. The motorized sheller was also preferred by farmers who have contractual agreements with the seed enterprise to supply maize seeds as they take an agreement with the enterprise not to shell the maize by their traditional methods except with their thumb or figure tip. Detaching the kernel from the cob by hand injured their finger tips (Figure 2). As they specified the Shellers avoid damage to palms and fingers and save their time. Further, in traditional methods maize is mostly shelled by women and children. However, the manual Sheller removes this demarcation and all family members can participate during different occasions when they are idle in their home. Even at coffee ceremony the thresher can use to shell both by male and female without any isolation. At all the Sheller avoids drudgery and saves their time reasonably.

Table 6 Financial analysis

\begin{tabular}{lllllll}
\hline Parameter & Trampling & Beating by stick & Stone rub & $\begin{array}{l}\text { Hand(thumb) } \\
\text { picking }\end{array}$ & Cylindrical & Motorized \\
\hline Output (tons) & 2.1 & 2.1 & 2.1 & 2.1 & 2.1 & 2.1 \\
Gross benefit (ETB) & 12600 & 12600 & 12600 & 12600 & 12600 & 12600 \\
Labor cost (ETB/yr) & 178.5 & 187 & 83.03 & & 123 & 12 \\
Cost of machine* & & & & & 2.4 & 4.39 \\
Maintenance cost & & & & & 4.39 \\
Depreciation (ETB) & & & & & 9.78 \\
Fuel and lubri. (ETB) & & $-* * * *$ & & & \\
Loss (ETB) & $-* * *$ & & & & \\
Damage (ETB) & & & & & \\
Total cost \& loss (ETB) & & & & & \\
Net benefit (ETB/yr) & & & & & \\
\hline
\end{tabular}

*It includes opportunity cost of investment within a year and depreciation 

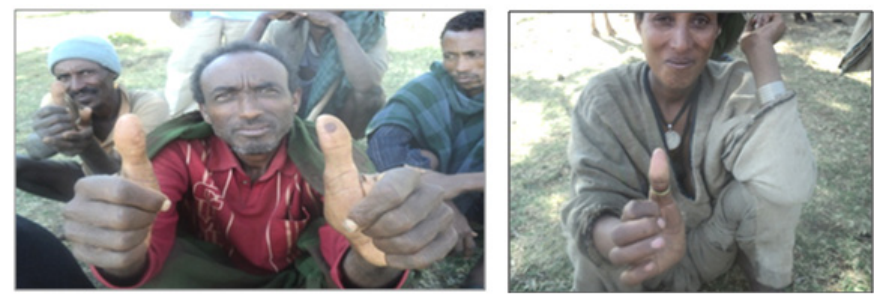

Figure 2 Bruised palms and fingers due to hand shelling.

\section{Conclusion and recommendation}

The shelling capacity of the cylindrical Sheller was more than two folds as compared with shelling by their thumb tip pressed on the grain to detach them from the ear. The hand held Maize Sheller reduces the time required for traditional shelling by more than half and it also protects from suffering or injuring of finger tip. Farmers were very interestred as the Sheller reduced their drudgery significantly. Farmers indicated that the sheller was best suit for shelling seed as it doesn't break or damage the grain. Farmers preferred motorized maize thresher. But the thresher is not available on individual basis under the smallholder and is uneconomical. So it should be given to farmers union or investors to fetch full advantage of the machine. Moreover options to enable the manual cylindrical thresher enable thresh different cob sizes and improvements be made in maneuvering so that farmers in remote areas could use it. Modifications on better feeding mechanism for motorized thresher, creation of an enabling inlet (e.g., making it circular) that hold the fed crop, the blowing system should be modified in such a way it avoids spreading and blow of dust on feeders, manual cylindrical Sheller should be presented in condition it shells both big and small sized maize cobs. Even if the motorized thresher has more economic benefits than the cylindrical Sheller and is the more preferred by farmers, its promotion and adoption will be negatively affected by the apparent reasons of mobility to remote areas, maintenance problems and management issues. Hence, we recommend the adoption of these two threshers for the different localities. ${ }^{6-14}$ Therefore, the technology should be scaled up for maize producers in large. A variation of efficiency of cylinderical sheller due to location associated with maize cob condition and ergonometric factors, the highly increasing pricetag of labor as well as the reduction of livestock size due to exclosures establsihment enforce the design and promotion of motorized thresher for the larger poulation. Further, we recommed future studies on postharvest loss of maize and intervetions aimed at reducing the loss should consider the lossess that incur at different stages and ways that these research activity was unable to estimate.

\section{Acknowledgements}

None.

\section{Conflicts of interest}

Author declares that there is no conflict of interest.

\section{References}

1. Sexena HK, Ajitha KR, Singh KR. Assessment of post-harvest storage losses in wheat: case study in East UttarPradesh. Indian Journal of Agricultural Marketing. 2000. p. 16-54.

2. Demeke M. Analysis of incentives and disincentives for maize in Ethiopia. Rome: Technical notes series, MAFAP, FAO; 2012. p. 1-36.

3. Danilo Mejia. Maize Post Harvest operation. FAO technical report. Ethiopia; 2003.

4. FAO Country Information Brief Ethiopia. Rome, Italy; 1995.

5. Dagninet A, Fentahun T, Abu T, et al. On-Farm Evaluation and Verification of Maize-Sorghum Thresher. Proceedings of the 3rd Annual Regional Conference on Completed Research Activities on Soil and Water Management, Forestry and Agricultural mechanization, 1-4 September, 2008. Ethiopia: ARARI, Bahir Dar; 2010. p. 227-236.

6. Abay G, Geta k. Test Report on Modification and Evaluation of Bako Model Kombolcha Modified Maize Sheller. Kombolcha, Ethiopia; 1996.

7. Abdul Shakoor K, Salin M. Rice Harvesting and Threshing. PAK J FOOD SCI. 2005; 15(1-2):45-52.

8. Alka S, Gautam US, Surendra P, et al. Ergonomic Evaluation of Farm women during Maize Shelling. Indian Res J Ext. 2010;10(3):41-44.

9. Agricultural Engineering in development-post harvest operations: Threshing and Shelling accessed. Ethiopia; 2014.

10. Herbst JH, Erickson DE. Farm Management. Principles, Budgets, Champaign, Illinois: Plans Stips Publishing LLC 1996.

11. Singh KP, Paradishi IL, Kumar M, et al. optimization of Machine parameters of a pedal-operated paddy thresher using RSM. Biosystems Engineering. 2008;100(4):591-600.

12. Assefa K, Alemu D, Shiratori K, et al. Challenges and Opportunities of Rice in Ethiopian Agricultural Development. FRG II Project Empowering Farmers' Innovation. Series No. 2. EIAR-JICA Cooperation, Ethiopia; 2011.

13. Montes ND, Alexis C, Rosario. Fulfilling the farmers' corn shelling needs: The UPLB corn Sheller. A technology and Market development study. 2009.

14. Shimelis Admassu. Post- harvest Sector Challenges and Opportunities in Ethiopia. Food Technologist, EARO. Addis Ababa, Ethiopia. 